\title{
3-Sulphinyl-5-Amino-1H-1,2,4-Triazoles as Inhibitors of Copper Corrosion
}

\author{
Dmitry Shevtsov ${ }^{1, *(D)}$, Oleg Kozaderov ${ }^{1}$, Khidmet Shikhaliev ${ }^{1}$, Ekaterina Komarova ${ }^{1}$, \\ Alexei Kruzhilin ${ }^{1}$, Andrei Potapov ${ }^{1} \mathbb{D}$, Chetti Prabhakar ${ }^{2}{ }^{\circledR}$ and Ilya Zartsyn ${ }^{1}$ \\ 1 Chemical Faculty Voronezh State University, Universitetskaya pl. 1, 394018 Voronezh, Russia; \\ ok@chem.vsu.ru (O.K.); shikh1961@yandex.ru (K.S.); komarova.ekaterina2312@yandex.ru (E.K.); \\ kruzhilin.alexey@gmail.com (A.K.); pistones@mail.ru (A.P.); zar-vrn@mail.ru (I.Z.) \\ 2 Department of Chemistry, National Institute of Technology, Kurukshetra 136119, Haryana, India; \\ chetti@nitkkr.ac.in \\ * Correspondence: shevtsov@chem.vsu.ru
}

Received: 22 October 2019; Accepted: 11 November 2019; Published: 14 November 2019

Featured Application: The authors suggest that the results can be used to protect copper from corrosion in acidic and neutral chloride environments. The resulting inhibitors effectively protect copper at low concentrations.

\begin{abstract}
A set of electrochemical and full-scale corrosion testing methods demonstrates that 3-sulphinylalkyl-5-amino-1H-1,2,4-triazoles can be used as inhibitors of copper corrosion in neutral chloride solutions and under atmospheric corrosion. It was shown that the inhibition effect of 3-sulphinylalkyl derivatives of 5-amino- $1 \mathrm{H}-1,2,4$-triazole increases with the growth of the chain of the additive. By means of the impedance spectroscopy method, the authors determined that the polarisation resistance and the Warburg impedance increases whereas the double-layer capacitance decreased with the growth of the inhibitor chain and the concentration of the inhibitor. In addition, the period when the first signs of corrosion attack appear on the copper plates in the salt spray chamber increased with the growth of the inhibitor chain and its concentrations. The lowest value of this period was measured for 3-sulphinylpropyl derivatives. However, it is still 12 times higher that this value measured without any inhibitors. Full-scale testing in $1 \% \mathrm{HCl}$ solution showed that the corrosion rate slows down by 10-20 times upon the introduction of the derivatives of 3-sulphinylbutyl and 3-sulphinylpentyl at a concentration of $\geq 5.00 \mathrm{mM}$. If the concentration of 3-phenethylsulphinyl is equal to or higher than $1.00 \mathrm{mM}$, then the protection level is about $85 \%$.
\end{abstract}

Keywords: copper; corrosion; chloride; 5-amino- $1 \mathrm{H}-1,2,4$-triazoles

\section{Introduction}

Due to its good thermal and electrical properties as well as resistance toward the influence of various chemical agents, copper has a wide range of industrial applications, electronics being one of them. Despite being quite a stable metal, copper is susceptible to dissolution or corrosion in aggressive aerated media, for instance, containing strong oxidants and acids. A protective passive layer is not formed in such media, which is why corrosion inhibitors should be used to prevent copper corrosion. Numerous studies of the possible inhibitors conducted to date have demonstrated that the most effective ones are organic compounds [1-11] acting as complex agents and adsorbates on the copper metal surface. Introducing heteroatoms such as nitrogen, sulphur, and oxygen with free electron pairs as well as multiple conjugated chemical bonds and aromatic rings containing delocalised $\pi$-electrons into the structure of an organic molecule can substantially improve its inhibiting effect. 
This is accounted for by the fact that vacant $\mathrm{d}$-orbitals in the atoms of copper can form coordinative bonds with heteroatoms and groups able to donate electrons, which results in effective chemisorption on the metal surface.

Nitrogen-containing azoles, e.g., benzotriazole [12,13] and benzimidazole [14], are the most common organic compounds that serve as inhibitors of copper corrosion in various media [15]. They get adsorbed on the copper surface and form a chemisorbed protective film. Sulphur-containing azole derivatives are excellent copper corrosion inhibitors in acidic media [16-18]. Taking into account the fact that the inhibition efficiency follows the sequence $\mathrm{O}<\mathrm{N}<\mathrm{S}$ [19], simultaneous introduction of a larger number of heteroatoms and groups into azole molecules is expected to yield a higher inhibition efficiency.

This has been confirmed by a number of theoretical and experimental studies in the field of inhibition of copper corrosion by sulphur-containing compounds. Quantum-chemical calculations showed [20] that the efficiency of 2-amino-5-mercapto-1,3,4-thiadiazole and 2-methyl-5-mercapto-1,3,4-thiadiazole as copper corrosion inhibitors in neutral chloride environments is higher than that of benzotriazole. Heterocyclic compounds containing several different functional groups, e.g., $\mathrm{OH}, \mathrm{N}=\mathrm{N}, \mathrm{C}=\mathrm{O}$, were observed to form $\mathrm{Cu}$ (II)-complexes [21] determining the protection properties of these organic molecules. 2-Amino-5-ethylthio-1,3,4-thiadiazole lowers the $\mathrm{Cu}$ corrosion rate greatly due to its strong adsorption onto the copper surface [22]. The strong adsorption of 1,3,4-thiadiazole [1], 1,2,4-triazole-3-thiole [4], and various mercapto-derivatives of tetrazole molecules on copper prevents the formation of soluble $\mathrm{Cu}$ chloride and oxychloride complexes in aerated chloride solutions, with the value of the inhibition efficiency being up to $100 \%$. The introduction of an aromatic ring into mercapto-derivatives of 1,2,3,4-tetrazole and the possibility of simultaneous formation of several bridges of $\mathrm{Cu}(\mathrm{I})$ ions with $\mathrm{N}$ and $\mathrm{S}$ atoms results in a higher corrosion resistance of $\mathrm{Cu}$ in $0.1 \mathrm{M} \mathrm{HNO}_{3}$ [7] and $1 \mathrm{mM} \mathrm{H}_{2} \mathrm{SO}_{4}$ [8] solutions. The efficiency of copper corrosion inhibition in hydrochloric acid increases in the row 3-amino-1,2,4-triazole $<3$-amino-mercapto-1,2,4-triazole $<$ 3-amino-5-methylthio-1,2,4-triazole [10], i.e., when an S-atom is introduced into the azole molecule, and its molecular weight increases. It was shown [23] that the hydrophilic mercapto-group in the substituted benzenethiol molecules has a high affinity for copper and the inhibitor molecules anchor on the $\mathrm{Cu}$ surface via the thiolate bond, while the hydrophobic benzene ring with different substituents constitutes the ultra-thin protective monolayer. 1-phenyl-2,5-dithiohydrazodicarbonamide has the maximum effectiveness as compared with thiosemicarbazide and phenyl isothiocyanate in copper corrosion inhibition in sodium chloride solution because it comprises four nitrogen atoms and two sulphur atoms and has a delocalised electron density at the same time [24].

The presence of multiple chemical bonds in the organic molecule, along with heteroatoms and aromatic rings, increases the anti-corrosion effect of the inhibitors even more. Indeed, the molecule with the highest molecular weight, having a phenyl group and an additional $\mathrm{N}=\mathrm{N}$ bond, was determined to be the best phthalazin derivative in copper corrosion inhibition in $1 \mathrm{M} \mathrm{H}_{2} \mathrm{SO}_{4}$ [25]. Hydrophobicity of mercaptopentylaminotriazoles enables them to be adsorbed on the copper surface, and as a result, to inhibit the anodic dissolution of copper in neutral chloride solutions at lower concentrations, as compared with 1-H-1,2,4-triazole and its amino derivatives [26].

In this paper, we studied the copper corrosion inhibition effect of new sulphinyl derivatives of 5-amino- $1 H-1,2,4$-triazole, the chemical composition and the structure of which combines the above described advantages of sulphur-containing derivatives of azoles and other $\mathrm{N}$-containing compounds. The studied inhibitors include three different heteroatoms (four N, sulphur, and oxygen), the functional group $\mathrm{S}=\mathrm{O}$, the presence of which presumably promotes the adsorption of the organic compound molecules on the copper surface, as well as hydrocarbon alkyl and phenethyl radicals, the introduction of which allows for variation of the molecular weight of the inhibitor. 


\section{Materials and Methods}

\subsection{Evaluation of Corrosion Inhibition Efficiency}

In order to evaluate the efficiency of the corrosion inhibition properties of the studied compounds, a set of electrochemical and full-scale corrosion testing methods was used. The metal surface was also analysed.

\subsection{Potentiodynamic Polarisation Measurements}

Electrochemical measurements were performed at room temperature $\left(\sim 25^{\circ} \mathrm{C}\right)$ on $\mathrm{M} 1$ electrodes in an unstirred borate buffer water solution $(\mathrm{pH} 7.4)$ with natural aeration in the presence of the inhibitor and $10 \mathrm{mM} \mathrm{NaCl}$. A classical electrolytic three-electrode cell was used in order to accelerate tie-dependent measurements. Derivatives of 3-sulphinyl-5-amino-1H-1,2,4-triazole synthesised at Voronezh State University were used. The technique was described in [27]. According to LCMS, the purity was at least $98 \%$. Their solubility in water is $>10 \mathrm{mM}$. Their names and structures are given in Table 1.

Table 1. Inhibitor names and structures.

\begin{tabular}{|c|c|c|}
\hline Symbol & Name & Formula \\
\hline A & 3-sulphinylpropyl-5-amino-1H-1,2,4-triazole & 0 \\
\hline B & 3-sulphinylbutyl-5-amino- $1 H$-1,2,4-triazole & $\mathrm{O}$ \\
\hline $\mathrm{C}$ & 3-sulphinylpentyl-5-amino- $1 H$-1,2,4-triazole & O \\
\hline $\mathrm{D}$ & 3-phenethylsulphinyl-5-amino- $1 H$-1,2,4-triazole & O \\
\hline
\end{tabular}

A saturated silver chloride reference electrode was placed in a separate container linked to the electrolytic cell by an agar-agar-based salt bridge filled with a potassium nitrate saturated solution. The auxiliary electrode was a platinum grid. The working copper electrode was polished by K3000 solid surface (grit of 5.2-6.2 $\mu \mathrm{m}$ ), degreased in 96\% ethanol, and washed with distilled water. The potentials of the working electrode $(E)$ are given according to the standard hydrogen electrode (SHE) scale. The current density $i$ was calculated by dividing the actual current $I$ by the geometric area of the working electrode $\left(0.75 \mathrm{~cm}^{2}\right)$.

Electrochemical measurements were performed using an IPC-PRO potentiostat (Frumkin Institute of Physical Chemistry and Electrochemistry Russian Academy of Sciences). In order to remove the oxide film appearing due to the air, the working Cu-electrode was polarised at $E=-0.60 \mathrm{~V}$ for $15 \mathrm{~min}$ prior to the experiment. The electrode was then held in the solution for about 3 to 5 min until the stable free corrosion potential $\left(E_{\mathrm{corr}}\right)$ was established. The working solution was then mixed with a $\mathrm{NaCl}$ solution while stirring so that the concentration of chloride ions would be $C_{\mathrm{Cl}^{-}}{ }^{-}=10 \mathrm{mM}$. The studied inhibitors were also added to the solution in a concentration of $C_{\mathrm{inh}}=0.01,0.10$, and $1.00 \mathrm{mM}$. 
After the new $E_{\text {corr }}$ value was established, the $I, E$ polarisation curve was registered by scanning the potential towards either the anode or the cathode direction at $0.2 \mathrm{mV} / \mathrm{sec}$. The activation potential $\left(E_{\text {act }}\right)$ was identified by a rapid increase in the current on the anode polarisation curve. Pits were then visually identified on the surface of the electrode. The measurement error for $E_{\text {act }}$ was below $0.03 \mathrm{~V}$.

The rate of corrosion in the current units $\left(i_{\text {corr }}\right)$ was determined by the polarisation resistance technique as summarized by Mansfeld $[28,29]$. The polarisation curve was previously registered by scanning the potential from $E=E_{\text {corr }}-0.03 \mathrm{~V}$ to $E=E_{\text {corr }}+0.03 \mathrm{~V}$ at $0.2 \mathrm{mV} / \mathrm{sec}$. The polarisation resistance $R_{p}$ was then calculated as the slope of the polarisation curve, replotted with $\Delta E, i$-coordinates $\left(\Delta E=E-E_{\text {corr }}\right)$, at $E_{\text {corr. }}$. The polarisation curve was then plotted with coordinates 2.3 $R_{p} \cdot i-\Delta E$, and the Tafel slopes of the half-reaction on the anode $b_{a}$ and the cathode $b_{c}$ was determined by means of the TableCurve program as the approximation parameter of the equation 2.3. $R_{\mathrm{p}} \cdot i=\frac{b_{\mathrm{a}} \cdot b_{\mathrm{c}}}{b_{\mathrm{a}}+b_{\mathrm{c}}}\left[\exp \left(\frac{\Delta E}{b_{\mathrm{a}}^{\prime}}\right)-\exp \left(\frac{\Delta E}{b_{\mathrm{c}}^{\prime}}\right)\right]$, which at $\Delta E=0$ gives $i_{\text {corr }}$. The measurements were performed at least 5 times for each of the studied concentrations of the inhibitor until reproducible data were obtained. The data were then statistically analysed.

The effectiveness of the inhibition activity of the derivatives of 5-amino- $1 \mathrm{H}-1,2,4$-triazole was evaluated judging by the protection level

$$
Z_{\mathrm{i}}=\frac{i_{\text {corr }, 0}-i_{\text {corr }, \text { inh }}}{i_{\text {corr }, 0}} \cdot 100 \%,
$$

where $i_{\mathrm{corr}, 0}$ and $i_{\mathrm{corr}, \text { inh }}$ are the corrosion current density with and without the inhibitor respectively.

\subsection{Electrochemical Impedance Spectroscopy (EIS)}

The electrochemical impedance spectroscopy (EIS) was performed using an IPC-PRO potentiostat with a frequency response analyser FRA-2. After $E_{\text {corr }}$ was stable for $30 \mathrm{~min}$, the frequency dependent impedance was registered within the range from 0.1 to $50 \mathrm{kHz}$ with no current. However, it was found that when the frequency increases more than $5 \mathrm{kHz}$, the Nyquist plot ceases to change. Therefore, the paper presents only data obtained at frequencies not exceeding $5 \mathrm{kHz}$. The analysis of the obtained results, the selection of the equivalent circuit, and the determination of its component values were carried out using DCS software.

\subsection{Accelerated Corrosion Test}

The experiments were carried out on copper plates with surface area $S=20 \times 50 \mathrm{~mm}^{2}$ and thickness $d=0.10 \mathrm{~mm}$, which were previously polished with K1000 abrasive paper and degreased in acetone. The protective inhibitor films were obtained by holding the copper plates in a water solution with the inhibitor for $60 \mathrm{~min}$ at $60^{\circ} \mathrm{C}$.

The experiments lasted 1 week $(168 \mathrm{~h})$. Three sample plates were held in an unstirred and naturally aerated of $1 \% \mathrm{HCl}$ solution all at the same time. The plates were then washed with distilled water and treated according to GOST 9.907-83 “Methods for the removal of corrosion products aftercorrosion tests". The rate of corrosion was determined according to the weight loss of the samples and calculated using the formula

$$
k=\frac{m_{0}-m}{S \cdot t} \cdot 100 \%,
$$

where $m_{0}$ and $m$ is the weight of the sample before and after the corrosion tests respectively. The effectiveness of the inhibition activity of the derivatives of 5-amino-1H-1,2,4-triazole was evaluated judging by the inhibition coefficient and the protection level

$$
\gamma=\frac{k_{0}}{k_{i n h}}
$$




$$
Z_{k}=\frac{k_{0}-k_{\text {inh }}}{k_{\text {inh }}} \cdot 100 \%,
$$

where $k_{0}$ and $k_{\text {inh }}$ are the rate of corrosion in the $\mathrm{HCl}$ solution with and without the inhibitor respectively. $k_{0}$ was $44.0 \mathrm{~g} / \mathrm{m}^{-2} / 24 \mathrm{~h}^{-1}$. The corrosion inhibition effect was studied for systems with the concentration of the inhibitor being $0.01,0.10$, and $1.00 \mathrm{mM}$.

The atmospheric corrosion of copper was accelerated by means of salt spray testing in order to determine the inhibition effect of derivatives of 5-amino-1H-1,2,4-triazole for inter-operational protection of copper products. The samples were placed in the chamber at $95 \%-100 \%$ relative air humidity. A 5\% solution of $\mathrm{NaCl}$ ( $\mathrm{pH}$ 6.5-7.2, GOST R 52763-2007) was sprayed into the chamber every hour. The samples were examined 3 times every $24 \mathrm{~h}$ in order to register the first signs of corrosion $\left(\tau_{\text {corr }}\right)$.

\subsection{Scanning Electron Microscopy (SEM)}

For microscopic analysis of the surface, a Jeol JSM-680LV raster electron microscope (Japan) was used together with Oxford Instrument INCA 250 X-ray microanalysis module (UK) which determines the chemical composition of the surface layer.

\subsection{Quantum-Chemical Simulation}

The computational methodology was as follows. All the four molecules were fully optimized using density functional theory (DFT) with B3LYP functional at 6-311 $+\mathrm{G}(\mathrm{d}, \mathrm{p})$ basis set in the programme Gaussian 16 [30]. These optimized structures have no imaginary frequencies and hence are situated at the lowest energy of the potential energy surface. The theoretical calculation also involves the determination of HOMO and LUMO energies and the energy gap along with ionization potential, electron affinity, electronegativity $(\chi)$, absolute hardness $(\eta)$, and softness $(\sigma)$ for all the molecules.

Following the density functional theory, $\eta$ is defined as [31]

$$
\eta=\frac{1}{2} \frac{\partial \mu}{\partial N}=\frac{1}{2} \frac{\partial^{2} E}{\partial N^{2}}
$$

where $\mu$ is the chemical potential, $N$ is the number of electrons, and $E$ is the energy. R.G. Pearson proposed [31] the following operational definition for absolute hardness:

$$
\eta=\frac{I P-E A}{2}
$$

where IP and $E A$ are ionization energy and electron affinity, respectively. According to Koopman's theorem, IP and $E A$ calculated from orbital energies are defined as

$$
I P=-U_{\mathrm{HOMO}}, E A=-U_{\mathrm{LUMO}}
$$

$E_{\mathrm{HOMO}}$ and $E_{\mathrm{LUMO}}$ are the energies of the highest occupied and the lowest unoccupied molecular orbitals. Based on the formula given above, the hardness can be represented as a measure of change resistance of the electron cloud of the chemical system. Softness $(\sigma)$ is defined as the reciprocal of hardness. This is an important parameter for chemical reactions since most reactive species have a higher softness value. Electronegativity $(\chi)$ is also defined in terms of energies of HOMO and LUMO as

$$
\chi=\frac{I P+E A}{2} .
$$

\section{Results and Discussion}

The results of measuring $E_{\text {corr }}$ of a copper electrode in a neutral chloride solution in the presence of sulphinylalkyl derivatives of 5-amino- $1 \mathrm{H}-1,2,4$-triazole are given in Table 2 . The change in $E_{\mathrm{corr}}$ 
with the increase in the concentration of the inhibitor was different for the studied compounds. Thus, with higher concentrations of inhibitor $\mathrm{A}, E_{\mathrm{corr}}$ shifted to the cathodic region. While the higher $C_{\mathrm{inh}}$ of inhibitor $\mathrm{B}$ results in a more noble corrosion potential. The concentration of inhibitor $\mathrm{C}$ has hardly any effect on $E_{\text {corr }}$. Thus, with concentrations of 0.01 and $0.10 \mathrm{mM}$, the value so $E_{\text {corr }}$ stays practically the same within the margin of error. With the maximum concentration of $1.00 \mathrm{mM}$ studied in this paper, $E_{\text {corr }}$ slightly shifts to the cathodic region (15-20 mV). The dependence of $E_{\text {corr }}$ on the concentration of inhibitor D is not symbatic.

Table 2. Open circuit potential $E_{\text {corr, }}$ polarisation resistance $R_{\mathrm{p}}$, corrosion current density $i_{\text {corr, }}$ and degree of protection of copper $Z_{i}$, in $10 \mathrm{mM} \mathrm{NaCl}$ solutions with various derivatives of 5-amino-1H-1,2,4-triazole.

\begin{tabular}{|c|c|c|c|c|c|}
\hline Inhibitor & $C_{\mathrm{inh}}, \mathrm{mM}$ & $E_{\text {corr }}, \mathrm{V}$ & $R_{\mathrm{p}}, \mathrm{k} \Omega \cdot \mathrm{cm}^{2}$ & $i_{\text {corr }} \mu \mathrm{A} \cdot \mathrm{cm}^{-2}$ & $Z_{i}, \%$ \\
\hline- & - & 0.172 & $41.9 \pm 4.6$ & $1.2 \pm 0.3$ & - \\
\hline \multirow{3}{*}{ A } & 0.01 & 0.198 & $20.8 \pm 4.8$ & $0.7 \pm 0.2$ & 41.7 \\
\hline & 0.10 & 0.140 & $25.9 \pm 1.7$ & $0.6 \pm 0.2$ & 50.0 \\
\hline & 1.00 & 0.128 & $107.2 \pm 17.7$ & $0.30 \pm 0.10$ & 75.0 \\
\hline \multirow{3}{*}{ B } & 0.01 & 0.162 & $34.8 \pm 5.3$ & $0.9 \pm 0.3$ & 25.0 \\
\hline & 0.10 & 0.226 & $62.6 \pm 8.4$ & $0.31 \pm 0.10$ & 74.2 \\
\hline & 1.00 & 0.295 & $115.8 \pm 18.3$ & $0.20 \pm 0.10$ & 83.3 \\
\hline \multirow{3}{*}{$\mathrm{C}$} & 0.01 & 0.174 & $42.4 \pm 7.3$ & $0.89 \pm 0.11$ & 25.8 \\
\hline & 0.10 & 0.179 & $140 \pm 19$ & $0.24 \pm 0.08$ & 80.0 \\
\hline & 1.00 & 0.160 & $172 \pm 13$ & $0.15 \pm 0.02$ & 57.5 \\
\hline \multirow{3}{*}{$\mathrm{D}$} & 0.01 & 0.159 & $223 \pm 33$ & $0.28 \pm 0.08$ & 76.6 \\
\hline & 0.10 & 0.136 & $208 \pm 23$ & $0.10 \pm 0.02$ & 91.7 \\
\hline & 1.00 & 0.210 & $195 \pm 17$ & $0.14 \pm 0.04$ & 88.3 \\
\hline
\end{tabular}

It is thus impossi ble define the whole group of sulphinylalkyl derivatives of 5-amino- $1 H-1,2,4$-triazole as either anodic, or cathodic inhibitors judging by the values of $E_{\text {corr }}$. Inhibitor A can be defined as a cathodic inhibitor and inhibitor B as an anodic inhibitor.

Polarisation curves of copper in neutral chloride solutions with the compounds under consideration are given in Figure 1.

The experiment carried out without the derivatives of 5-amino- $1 H-1,2,4$-triazole demonstrated that the peak current density of $+0.35 \mathrm{~V}$ was present in the anodic region of the polarisation curve, which then shifted to the passivation region with $E_{\mathrm{act}} \approx+0.71 \mathrm{~V}$. For inhibitors $\mathrm{A}-\mathrm{C}$, the potential $E_{\text {act }}$ shifts to the anodic region at any concentration studied. This fact is considered in [32,33] as the inhibition effect of the additive. The potential $E_{\text {act }}$ increases with the additive concentration. For inhibitor $\mathrm{D}$ the potential $E_{\text {act }}$ does not exceed the value observed without an inhibitor, when $C_{\text {inh }}=$ $0.01-1.00 \mathrm{mM}$, and practically equals the value without an inhibitor when $C_{\mathrm{inh}}=1.00 \mathrm{mM}$. Pits on the surface of the electrode at the activation potential point were only formed in the experiment without the derivatives of 5-amino- $1 H-1,2,4$-triazole. When the inhibitors were present, no pits were observed on the metal surface.

The value of the maximum current density on the anodic curve decreases with higher $C_{\text {inh }}$ and the growth of the sulphinylalkyl chain (Figure 1a-d, curves 1-4). The value of the maximum current density was greater relative to the experiment without an inhibitor at $C_{\mathrm{inh}}=0.01 \mathrm{mM}$ in the presence of inhibitors $\mathrm{A}-\mathrm{C}$, and $C_{\mathrm{inh}}=0.10 \mathrm{mM}$ in the presence of $\mathrm{A}$. There is no active dissolution area for $\mathrm{B}, \mathrm{C}$ at $C_{\mathrm{inh}}=1.00 \mathrm{mM}$ and for $\mathrm{D}$ at $C_{\mathrm{inh}} \geq 0.10 \mathrm{mM}$. The inhibition effect is also demonstrated by the fact that either there is no anodic current maximum on the polarisation curve, or it decreases when the inhibitors are used [34]. The current density in the passivation region is also lower when the compounds are added to the solution. 


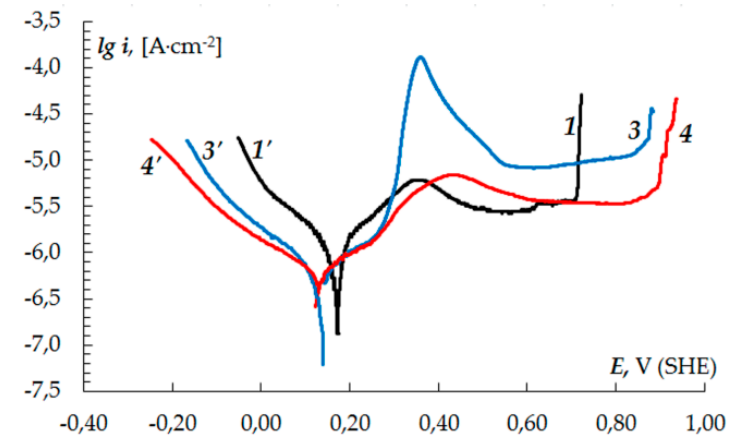

(a)

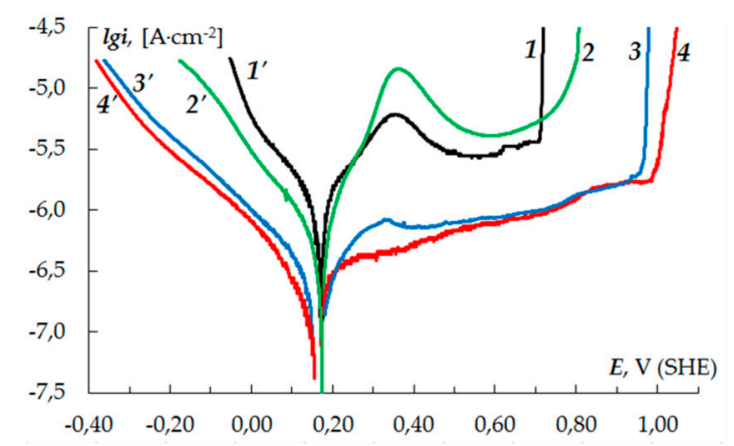

(c)

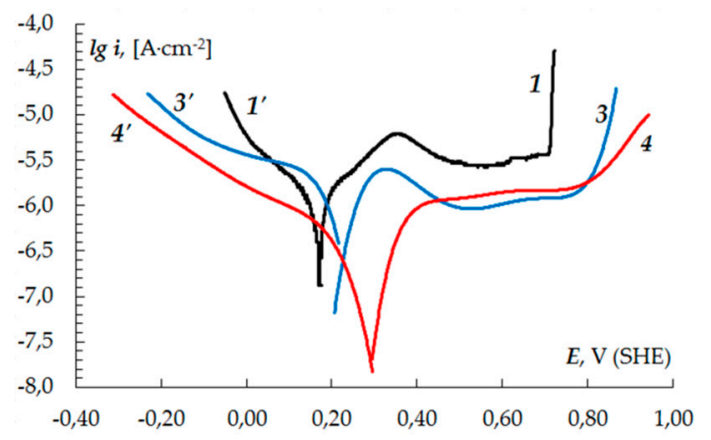

(b)

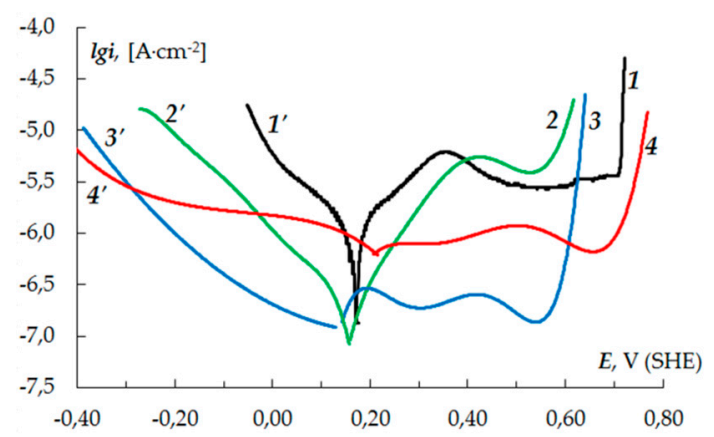

(d)

Figure 1. Anodic and cathodic polarisation curves of copper in a borate buffer (pH 7.4) with $0.01 \mathrm{M} \mathrm{NaCl}$ and 3-sulphinylpropyl-5-amino-1H-1,2,4-triazole (a), 3-sulphinylbutyl-5-amino- $1 H$-1,2,4-triazole (b), 3-sulphinylpentyl-5-amino- $\mathrm{H}$-1,2,4-triazole (c) and 3-phenethylsulphinyl-5-amino- $\mathrm{H}$-1,2,4-triazole (d) at the following concentrations: $1,1^{\prime}-0 ; 2,2^{\prime}-0.01 \mathrm{mM} ; 3,3^{\prime}-0.10 \mathrm{mM} ; 4,4^{\prime}-1.00 \mathrm{mM}$.

The difference between cathodic curves of copper in solutions with and without A-C becomes noticeable only when $C_{\text {inh }} \geq 0.10 \mathrm{mM}$. The higher the concentration of the inhibitor, the lower the current density (Figure 1a-c, curves $3^{\prime}-4^{\prime}$ ). This means that the cathodic process is slowing down. The region of the rapid growth of the cathodic current density is shifted towards negative values by at least $0.1 \mathrm{~V}$ for inhibitor $\mathrm{A}$ and at least $0.25 \mathrm{~V}$ for inhibitors $\mathrm{B}$ and $\mathrm{C}$, as compared to that of the chloride solution without inhibitors. For inhibitor D, the shift is observed at any of the studied concentrations.

The analysis of the polarisation resistance $R_{\mathrm{p}}$, the rate of corrosion, and the protection level determined by the potentiodynamic polarisation method (Table 2) demonstrated that the inhibition effect of all the studied 3-sulphinylalkyl derivatives of 5-amino-1H-1,2,4-triazole depends on their concentration. The maximum protection level is observed when $C_{\text {inh }} \geq 0.10 \mathrm{mM}$ (for inhibitor $\mathrm{A}$ at $C_{\text {inh }} \geq 1.00 \mathrm{mM}$ ). In this case $R_{\mathrm{p}}$ increases by $2-4$ times and the corrosion rate decreases by $4-10$ times. When the concentration of a compound is $0.01 \mathrm{mM}$, the inhibition effect for inhibitors A-C is weaker (below $40 \%$ of the effect observed during the test experiment). The exception is inhibitor D. At $C_{\text {inh }} \geq$ $0.01 \mathrm{mM}$ the rate of corrosion is 4 times slower. Generally, the inhibition effect on copper in neutral chloride solutions increases with the growth of the sulphinylalkyl chain.

Comparison of the results obtained for compounds with the similar structure, e.g., for 2-amino-5-(ethylthio)-1,3,4-thiadiazole [1] suggests an increase in the degree of protection during the transition of mercapto-derivatives to sulfinyl-derivatives.

The electrochemical impedance spectroscopy also proves that a protective film forms on copper in neutral chloride solutions with 3-sulphinylalkyl-5-amino- $1 \mathrm{H}-1,2,4$-triazoles. Figure 2 presents Nyquist diagrams obtained for the chloride-borate solution without (Figure 2a-d, 1) and with the A, B, C, and $\mathrm{D}$ inhibitors with concentrations of $C_{\mathrm{inh}}=0.01-1.00 \mathrm{mM}$ (Figure $\left.2 \mathrm{a}-\mathrm{d}, 2-4\right)$. The Nyquist plots are presented as an imperfect semicircle, the imperfection being usually accounted for by the impedance frequency dispersion and the geometric and/or energetic inhomogeneity of the electrode's surface. 
When the organic additives are added to the neutral solution or when $C_{\text {inh }}$ increases, the shape of the impedance diagram does not change but the radius of the semicircle increases significantly. The radius change is obtained for substances $\mathrm{A}$ and $\mathrm{B}$ with increasing additive concentration. For substances $\mathrm{C}$ and $\mathrm{D}$, the radii of the semicircles are close for all the studied concentrations. In the region of low frequencies, the curvature of all the Nyquist plot increases and tends to be linear, which is accounted for by the transport problems of the electrochemical process.

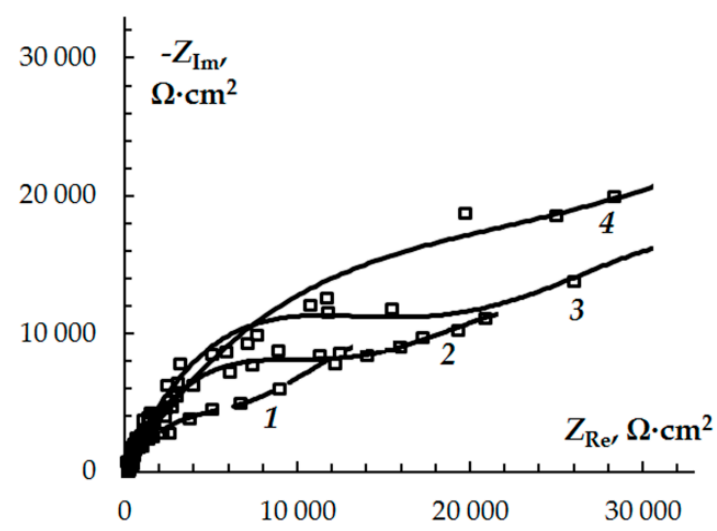

(a)

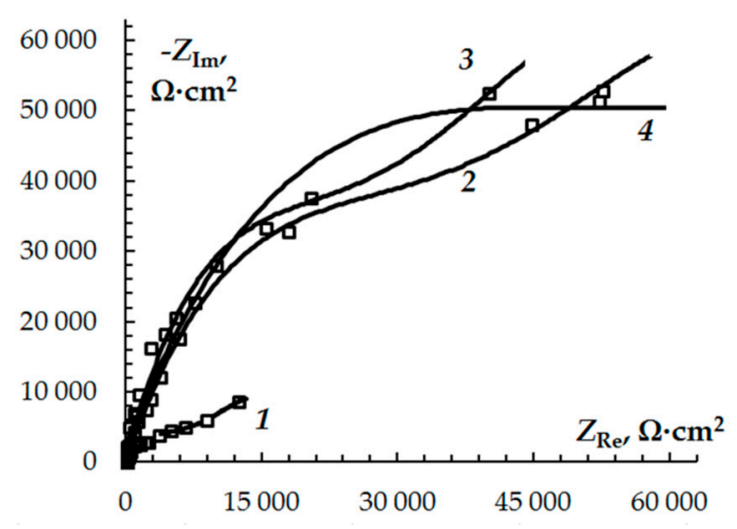

(c)

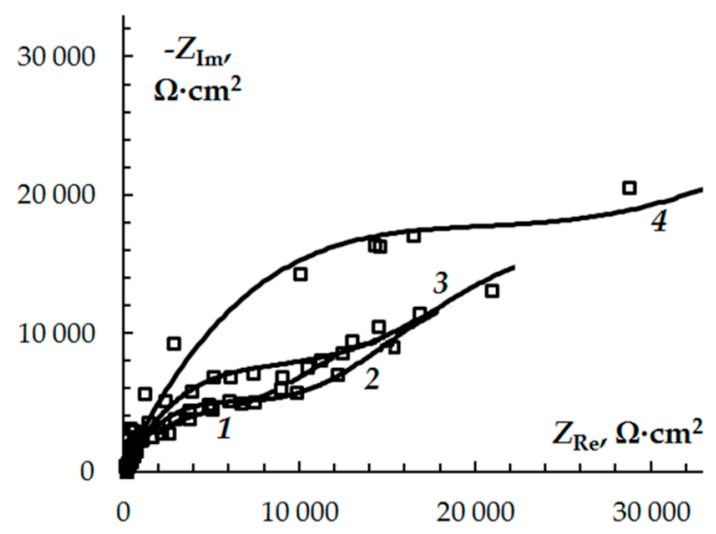

(b)

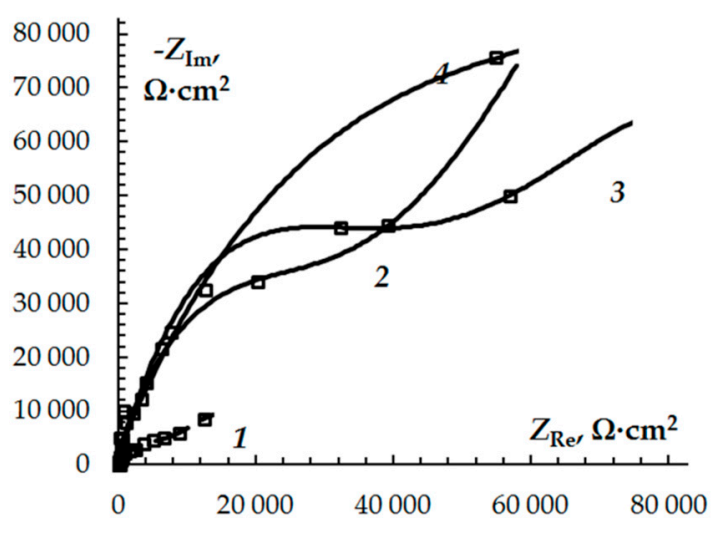

(d)

Figure 2. The Nyquist diagrams of copper in borate buffer (pH 7.4) $+10 \mathrm{mM} \mathrm{NaCl}$ in the presence of 3-sulphinylpropyl-5-amino-1 $H$-1,2,4-triazole (a), 3-sulphinylbutyl-5-amino-1H-1,2,4-triazole (b), 3-sulphinylpentyl-5-amino- $1 \mathrm{H}-1,2,4$-triazole (c) and 3-phenethylsulphinyl-5-amino-1H-1,2,4-triazole (d) at concentrations of 0.01 (1), 0.10 (2), and $1.00 \mathrm{mM}$ (3).

A regression analysis of the impedance spectroscopy data was used to determine the most probable equivalent circuit modeling the processes at the interface copper-solution (Figure 3).

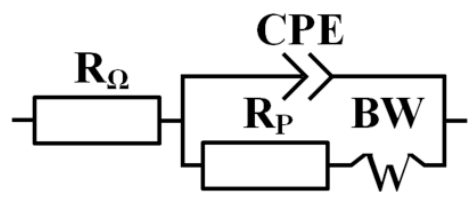

Figure 3. The equivalent circuit model used to fit the EIS response $\left(R_{\Omega}\right.$-direct-current resistance, $C P E$ - constant phase element, $R_{\mathrm{p}}$-polarisation resistance of the electrochemical reaction, $B W$-Warburg impedance). 
Table 3 presents the values of the following circuit elements: $R_{\Omega}$ (direct-current resistance of the solution), $C P E$ (constant phase element), $R_{\mathrm{p}}$ (polarisation resistance of the electrochemical reaction), and $B W$ (Warburg impedance). Admittance for constant phase element is described as

$$
Y_{\mathrm{CPE}}=Y_{0}(\mathrm{j} \omega)^{n}
$$

where $\mathrm{j}$ is the imaginary root, $\omega$ the angular frequency, $Y_{0}$ the magnitude and $n$ is the exponential term.

Table 3. Equivalent circuit elements and degree of protection of copper electrode in $10 \mathrm{mM} \mathrm{NaCl}$ solutions with various derivatives of 5-amino- $1 H-1,2,4$-triazole.

\begin{tabular}{|c|c|c|c|c|c|c|c|}
\hline Inhibitor & $C_{\mathrm{inh}}, \mathrm{mM}$ & $\begin{array}{c}R_{\Omega} \\
\Omega \cdot \mathrm{cm}^{2}\end{array}$ & $\underset{\mathrm{Y}_{0,}^{-1} \cdot \mathrm{cm}^{-2} \cdot \mathrm{s}^{\mathrm{n}}}{\mathrm{CP}}$ & $n$ & $\begin{array}{c}\mathrm{R}_{\mathrm{p}}^{\mathrm{EIS}} \\
\mathrm{k} \Omega \cdot \mathrm{cm}^{2}\end{array}$ & $\begin{array}{c}B W, \\
\mathrm{k} \Omega \cdot \mathrm{cm}^{2} \cdot \mathrm{s}^{-0,5}\end{array}$ & $\begin{array}{c}\text { Degree of protection, } \\
\eta_{\text {inh }} \%\end{array}$ \\
\hline- & 0.00 & 214 & $6.39 \times 10^{-6}$ & 0.86 & 10.06 & 12.43 & - \\
\hline \multirow{3}{*}{ A } & 0.01 & 195 & $5.86 \times 10^{-6}$ & 0.86 & 24.07 & 11.80 & 58.2 \\
\hline & 0.10 & 200 & $3.71 \times 10^{-6}$ & 0.91 & 27.14 & 14.84 & 62.9 \\
\hline & 1.00 & 187 & $2.80 \times 10^{-6}$ & 1.00 & 41.23 & 0.085 & 75.6 \\
\hline \multirow{3}{*}{ B } & 0.01 & 179 & $1.36 \times 10^{-6}$ & 0.92 & 12.88 & 19.49 & 21.8 \\
\hline & 0.10 & 184 & $2.90 \times 10^{-6}$ & 0.83 & 16.60 & 14.69 & 39.3 \\
\hline & 1.00 & 179 & $1.92 \times 10^{-6}$ & 0.93 & 43.65 & 41.62 & 76.9 \\
\hline \multirow{3}{*}{$\mathrm{C}$} & 0.01 & 143 & $4.10 \times 10^{-6}$ & 0.88 & 65.48 & 43.70 & 84.6 \\
\hline & 0.10 & 150 & $1.55 \times 10^{-6}$ & 0.98 & 83.79 & 82.75 & 88.0 \\
\hline & 1.00 & 155 & $3.40 \times 10^{-6}$ & 0.87 & 101.02 & 35.20 & 90.0 \\
\hline \multirow{3}{*}{$\mathrm{D}$} & 0.01 & 145 & $2.29 \times 10^{-6}$ & 0.98 & 63.24 & 32.44 & 84.2 \\
\hline & 0.10 & 145 & $1.27 \times 10^{-6}$ & 1.00 & 76.70 & 59.95 & 86.9 \\
\hline & 1.00 & 140 & $1.07 \times 10^{-6}$ & 1.00 & 115.01 & 99.46 & 91.3 \\
\hline
\end{tabular}

$R_{\mathrm{p}}$ is significantly higher in solutions with an organic additive and increases when $C_{\mathrm{inh}}$. We can thus say that the changes in the Nyquist plot are most probably caused by the decrease in the double-layer capacitance resulting from the adsorption of the inhibitor molecules at the interface copper/solution on the one hand, and the increase in the polarisation resistance resulting from the formation of a protective film on the copper surface on the other. Additional evidence for the formation of the film is the rapid growth of Warburg impedance in the presence of the inhibitor (Table 3). This means either that the diffusion of the soluble corrosion product on the electrode's surface slows down, or that the barrier properties of the protective film blocking the aggressive elements of the solution increase. Linear segments were not obtained on the Nyquist plots (plot 4 in Figure 2c,d) at high frequencies. The observed non-linearity can be associated with the formation of a film of organic matter on the surface of copper.

The inhibition efficiency $\left(\eta_{\text {inh }}, \%\right)$

$$
\eta_{\text {inh }}=\left(1-\frac{R_{\mathrm{p}, 0}^{E I S}}{R_{\mathrm{p}, \text { inh }}^{E I S}}\right) \cdot 100 \%
$$

was calculated using the values of charge transfer resistance without $\left(R_{\mathrm{p}, 0}^{E I S}\right)$ and with the inhibitor $\left(R_{\mathrm{p}, \text { inh }}^{\text {EIS }}\right)$. Efficiency values for inhibitors $\mathrm{A}$ and $\mathrm{B}$ are below $70 \%$, while for compounds $\mathrm{C}$ and $\mathrm{D}$, they are up to $89 \%$ (Table 3). This agrees well with the results of the corrosion rate calculations based on the analysis of the polarisation curves carried out using the Mansfeld method (Table 2).

The same results were obtained during the salt spray testing (Table 4). The period when the first signs of corrosion attack appear $\tau_{\text {corr }}$, with the inhibitor concentration within the range of 1 to $10 \mathrm{mM}$, is longer and can be presented as follows: inhibitor $\mathrm{A}<$ inhibitor $\mathrm{B}<$ inhibitor $\mathrm{C}<$ inhibitor D. $\tau_{\text {corr }}$ increases with higher $C_{\text {inh }}$ and reaches $2-4$ days at $10 \mathrm{mM}$, which proves the effectiveness of 3-sulphinylalkyl derivatives of 5-amino-1H-1,2,4-triazole for copper in moist atmosphere. 
Table 4. Results of the copper natural corrosion tests.

\begin{tabular}{|c|c|c|c|c|c|}
\hline Inhibitor & $C_{\mathrm{inh}}, \mathrm{mM}$ & $k, \mathrm{~g} / \mathrm{m}^{2} / \mathrm{day}^{-1}$ & $\gamma$ & $Z_{k}, \%$ & $\tau_{\text {corr }}, \mathrm{h}$ \\
\hline- & - & 44 & - & - & $1-2$ \\
\hline \multirow{3}{*}{ A } & 1.0 & 17.3 & 1.3 & 22.9 & 26 \\
\hline & 5.0 & 13.7 & 1.6 & 38.9 & 43 \\
\hline & 10.0 & 10.3 & 2.2 & 54.1 & 43 \\
\hline \multirow{3}{*}{ B } & 1.0 & 18.4 & 1.2 & 17.8 & 47 \\
\hline & 5.0 & 5.9 & 3.8 & 73.9 & 63 \\
\hline & 10.0 & 4.3 & 5.2 & 80.9 & 63 \\
\hline \multirow{3}{*}{ C } & 1.0 & 22.4 & 1.0 & 0.0 & 68 \\
\hline & 5.0 & 4.7 & 4.8 & 79.0 & 86 \\
\hline & 10.0 & 2.3 & 9.8 & 89.8 & 117 \\
\hline \multirow{3}{*}{ D } & 1.0 & 0,9 & 10,9 & 90,8 & 70 \\
\hline & 5.0 & 0,7 & 13,1 & 92,4 & 95 \\
\hline & 10.0 & 1,5 & 6,4 & 84,3 & 100 \\
\hline
\end{tabular}

A series of full-scale natural corrosion tests in $1 \% \mathrm{HCl}$ solution demonstrated that with a higher concentration of the inhibitor and the growth of the chain, the additive the rate of copper corrosion decreases. The highest protection level of up to $90 \%$ results from inhibitor D at any concentration within the range of 0.01 to $1.00 \mathrm{mM}$.

Additional proof is provided by the images of the surface of copper electrodes held in the salt spray chamber (Figure 4). In the presence of the inhibitor, the surface of the copper electrode remains bright and smooth even if the concentration of the organic additive is minimal (Figure 4c). Without the inhibitors, the surface of the electrode darkens (Figure $4 \mathrm{~b}$ ) and corrosion spots appear.
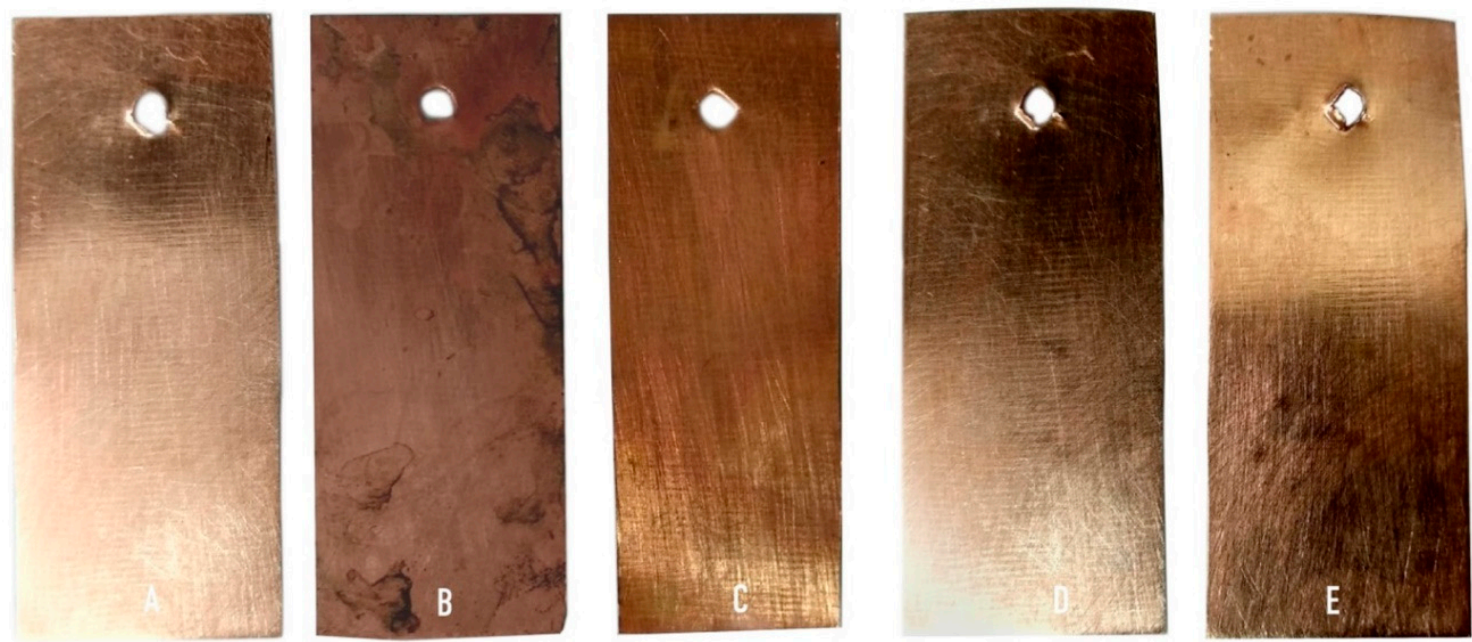

Figure 4. Copper samples before (A) and after salt spray corrosion testing without an inhibitor (B) and in the presence of 3-phenethylsulphinyl-5-amino- $1 H$-1,2,4-triazole at concentrations of 0.01 (C), 0.10 (D), $1.00 \mathrm{mM}(\mathbf{E})$.

To explain this effect, we carried out scanning electron microscopy and analysed the micrographs of the copper electrode surface taken before and after potentiodynamic anodic polarisation in a neutral chloride solution (Figure 5). Without the inhibitors, multiple corrosion spots of about 5-10 $\mathrm{mM}$ appear on the surface. However, when the copper is polarised in the solution with $1 \mathrm{mM}$ of 3-phenethylsulphinyl-5-amino-1H-1,2,4-triazole (inhibitor D), no pits can be observed on the surface. The micrographs only show scratches left from polishing the electrode. 


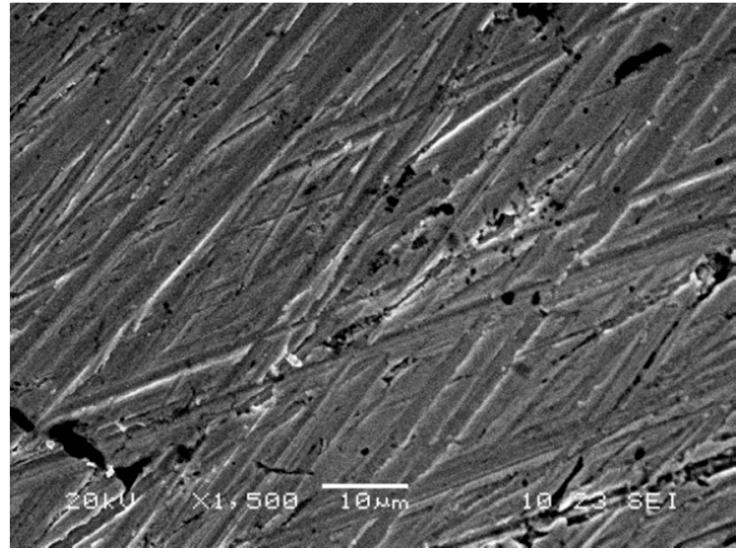

(a)

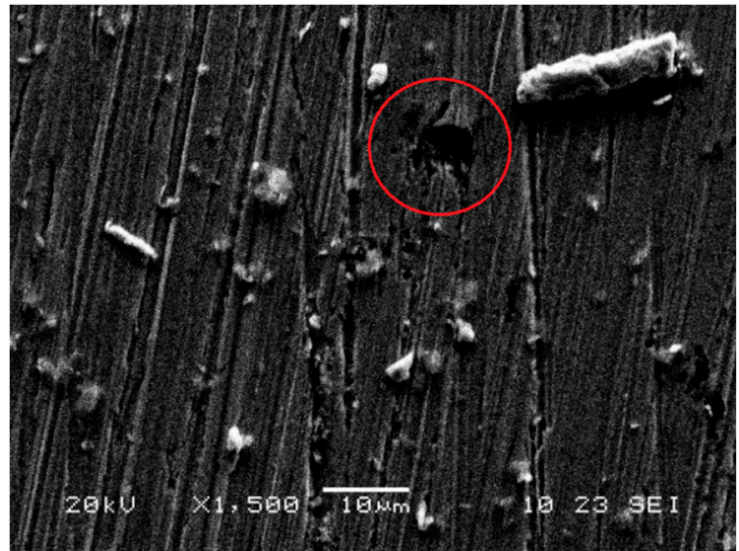

(b)

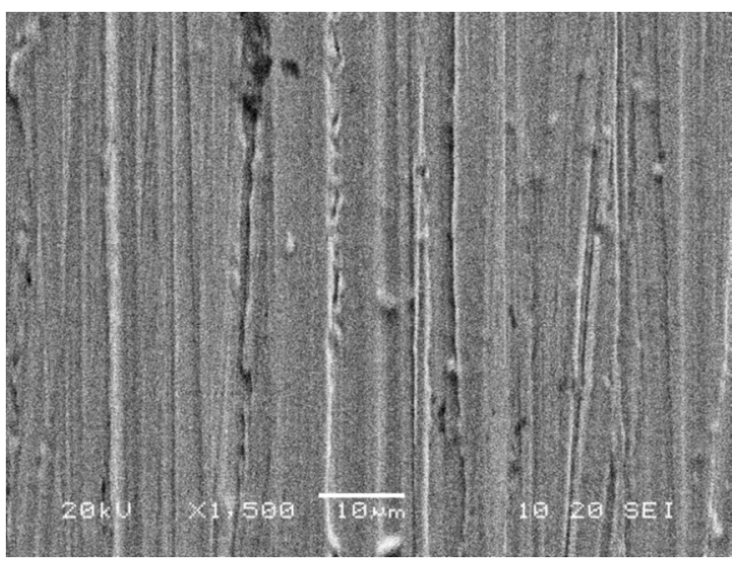

(c)

Figure 5. SEM micrographs of copper surface before polarisation (a), after polarisation in borate buffer $(\mathrm{pH} 7.4)+10 \mathrm{mM} \mathrm{NaCl}(\mathbf{b})$, after polarisation in borate buffer $(\mathrm{pH} 7.4)+10 \mathrm{mM} \mathrm{NaCl}+1.00 \mathrm{mM}$ of 3-phenethylsulphinyl-5-amino-1H-1,2,4-triazole (c).

The results of the analysis of the elemental composition of the surface layer of the copper electrode before and after anodic polarisation are given in Table 5. Quite notably, the introduction of the organic additives results in a significant decrease in the amount of oxygen on the copper surface, which may be accounted for by the fact that the metal oxidation slows down due to the slowdown of the anodic process.

Table 5. Elemental surface composition (at. \%) of the copper electrode.

\begin{tabular}{ccc}
\hline Polarisation Mode & \multicolumn{2}{c}{ Element } \\
\cline { 2 - 3 } & $\mathbf{C u}$ & $\mathbf{O}$ \\
\hline No polarisation & 100.0 & 0.0 \\
After polarisation in borate buffer $+10 \mathrm{mM} \mathrm{NaCl}$ & 47.2 & 52.8 \\
After polarisation in borate buffer + 10 $\mathrm{mM} \mathrm{NaCl}+1.00 \mathrm{mM}$ & 93.1 & 6.9 \\
of 3-phenethylsulphinyl-5-amino-1H-1,2,4-triazole & & \\
\hline
\end{tabular}

The optimized geometries of all the molecules consider for the study are shown in Figure 6. 


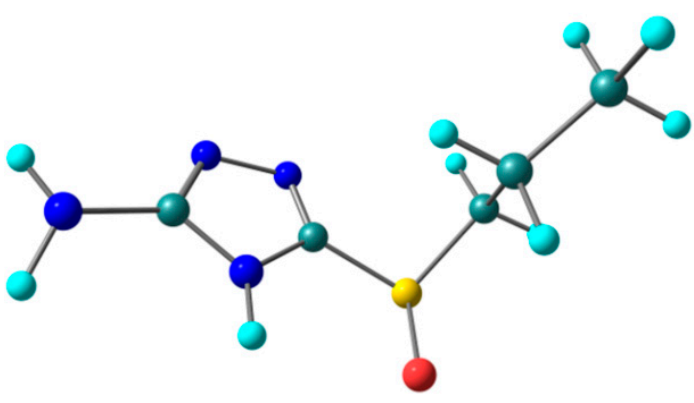

(A)

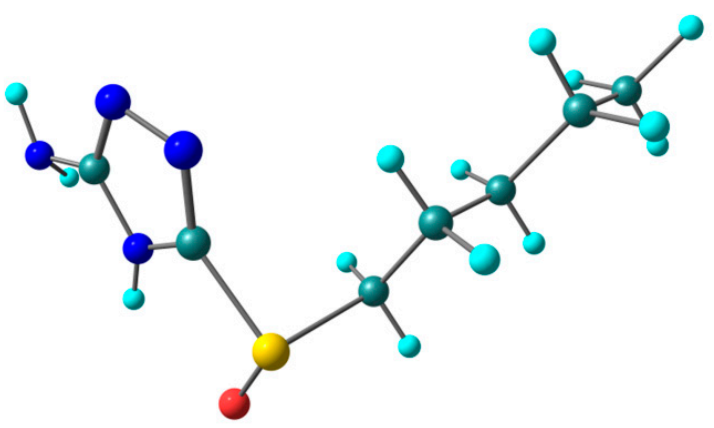

(C)



(B)

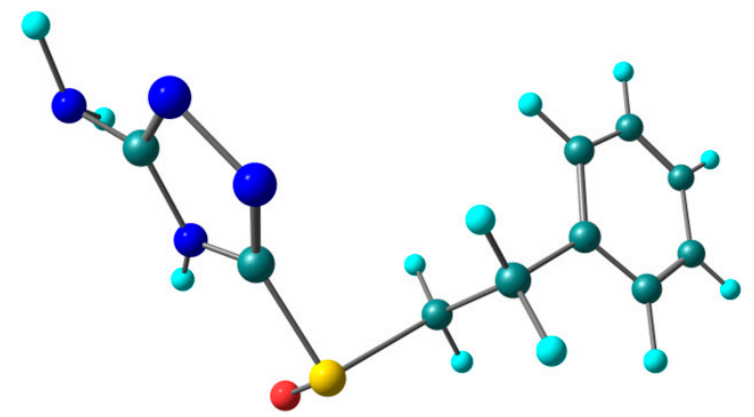

(D)

Figure 6. Optimized structures of the molecules considered for study: (A) - 3-sulphinylpropyl-5-amino -1H-1,2,4-triazole; (B) - 3-sulphinylbutyl-5-amino-1H-1,2,4-triazole; (C) - 3-sulphinylpentyl-5-amino-1H1,2,4-triazole; (D) - 3-phenethylsulphinyl-5-amino-1H-1,2,4-triazole.

Table 6 gives the values of the ionization potential, electron affinity, electronegativity, absolute hardness and softness in eV calculated at B3LYP/6-311+ $\mathrm{G}(\mathrm{d}, \mathrm{p})$ and optimized geometry. The HOMO and LUMO energies of molecule $(\mathrm{A})$ are $-6.55 \mathrm{eV}$ and $-0.68 \mathrm{eV}$ and the corresponding HOMO-LOMO gap is $5.87 \mathrm{eV}$. The introduction of one more methyl group, i.e., changing side chain propyl to butyl (molecule (B)) and butyl to pentyl (molecule (C)) results in destabilization of both HOMO and LUMO levels, leading to HOMO-LOMO gaps of $5.85 \mathrm{eV}$ and $5.86 \mathrm{eV}$ for molecules (B) and (C) respectively. However, the ethylbenzene substituted molecule, i.e., molecule $\mathrm{D}$ demonstrates the smallest HOMO-LOMO gap of $5.72 \mathrm{eV}$ due to greater destabilization of the LUMO level. Moreover, molecule $(\mathrm{D})$ shows the smallest value of hardness $(2.86 \mathrm{eV})$ and the highest electronegativity $(3.72 \mathrm{eV})$ of all the molecules.

Table 6. Calculated energies of HOMO, LUMO, HOMO LUMO gaps (HLG), ionization potential (IP), electron affinity (EA), electronegativity $(\chi)$, absolute hardness $(\eta)$ and softness $(\sigma)$ in eV at B3LYP/6-311 $+\mathrm{G}(\mathrm{d}, \mathrm{p})$ level.

\begin{tabular}{ccccccccc}
\hline Molecule & HOMO & LUMO & HLG & IP & EA & $\chi$ & $\eta$ & $\sigma$ \\
\hline A & -6.55 & -0.68 & 5.87 & 6.55 & 0.68 & 3.62 & 2.94 & 0.34 \\
B & -6.57 & -0.72 & 5.85 & 6.57 & 0.72 & 3.64 & 2.92 & 0.34 \\
C & -6.57 & -0.71 & 5.86 & 6.57 & 0.71 & 3.64 & 2.93 & 0.34 \\
D & -6.58 & -0.86 & 5.72 & 6.58 & 0.86 & 3.72 & 2.86 & 0.35 \\
\hline
\end{tabular}

\section{Conclusions}

This study demonstrates that 3-sulphinylalkyl derivatives of 5-amino-1H-1,2,4-triazole can be used as copper corrosion inhibitors in neutral and hydrochloric acid solutions. Their protective effect increases with the growth of the alkyl chain and with higher concentrations of the additive and reaches its maximum $(\approx 90 \%)$ at $\mathrm{C}_{\mathrm{inh}} \geq 0.10 \mathrm{mM}$. The best protective effect is demonstrated 
by 3-phenethylsulphinyl-5-amino-1 $H$-1,2,4-triazole, which comprises four $\mathrm{N}$, an $\mathrm{S}=\mathrm{O}$ group and a benzene ring.

The scanning electron microscopy showed that after the introduction of the derivatives of 5-amino- $1 H-1,2,4$-triazole, the pitting process stops and the amount of oxygen on the surface of the copper electrode decreases.

The fact that a protective film actually forms on the copper surface is proven by a decrease in the double-layer capacitance, an increase in the polarisation resistance of the copper electrode, and an increase in the Warburg impedance upon the introduction of the inhibitor.

Author Contributions: Conceptualization, I.Z.; Investigation, D.S., A.K., E.K. and A.P.; Methodology, A.K., E.K. and A.P.; Project administration, K.S.; Software, C.P.; Writing—original draft, O.K., D.S. and A.K.; Writing-review \& editing, K.S., C.P. and I.Z.

Funding: This study received financial support from the Ministry of Education and Science of the Russian Federation within the framework of State Contract with universities regarding scientific research in 2017-2019, project No. 4.3633.2017/4.6.

Conflicts of Interest: The authors declare no conflict of interest.

\section{References}

1. Sherif, E.S.M. Effects of 2-amino-5-(ethylthio)-1,3,4-thiadiazole on copper corrosion as a corrosion inhibitor in 3\% NaCl solutions. Appl. Surf. Sci. 2006, 252, 8615-8623. [CrossRef]

2. Sherif, E.M.; Park, S.M. 2-Amino-5-ethyl-1,3, 4-thiadiazole as a corrosion inhibitor for copper in $3.0 \% \mathrm{NaCl}$ solutions. Corros. Sci. 2006, 48, 4065-4079. [CrossRef]

3. Sherif, E.M.; Erasmus, R.M.; Comins, J.D. Corrosion of copper in aerated synthetic sea water solutions and its inhibition by 3-amino-1,2,4-triazole. J. Colloid Interface Sci. 2007, 309, 470-477. [CrossRef] [PubMed]

4. Sherif, E.M.; Shamy, A.M.E.; Ramla, M.M.; El Nazhawy, A.O. 5-(Phenyl)-4H-1, 2, 4-triazole-3-thiol as a corrosion inhibitor for copper in 3.5\% NaCl solutions. Mater. Chem. Phys. 2007, 102, 231-239. [CrossRef]

5. Abdullah, A.M.; Al-Kharafi, F.M.; Ateya, B.G. Intergranular corrosion of copper in the presence of benzotriazole. Scr. Mater. 2006, 54, 1673-1677. [CrossRef]

6. Elmorsi, M.A.; Hassanein, A.M. Corrosion inhibition of copper by heterocyclic compounds. Corros. Sci. 1999, 41, 2337-2352. [CrossRef]

7. Mihit, M.; Salghi, R.; Issami, S.E.; Bazzi, L.; Hammouti, B.; Addi, E.A.; Kertit, S. A study of tetrazoles derivatives as corrosion inhibitors of copper in nitric acid. Pigment Resin Technol. 2006, 35, 151-157. [CrossRef]

8. Szőcs, E.; Vastag, G.; Shaban, A.; Kálmán, E. Electrochemical behaviour of an inhibitor film formed on copper surface. Corros. Sci. 2005, 47, 893-908. [CrossRef]

9. Tromans, D.; Sun, R.H. Anodic polarisation behavior of copper in aqueous chloride/benzotriazole solutions. J. Electrochem. Soc. 1991, 138, 3235-3244. [CrossRef]

10. Lalitha, A.; Ramesh, S.; Rajeswari, S. Surface protection of copper in acid medium by azoles and surfactants. Electrochim. Acta 2005, 51, 47-55. [CrossRef]

11. Otmačić, H.; Stupnišek-Lisac, E. Copper corrosion inhibitors in near neutral media. Electrochim. Acta 2003, 48, 985-991. [CrossRef]

12. Yu, P.; Liao, D.M.; Luo, Y.B.; Chen, Z.G. Studies of benzotriazole and tolytriazole as inhibitors for copper corrosion in deionized water. Corrosion 2003, 59, 314-318. [CrossRef]

13. Qafsaoui, W.; Blanc, C.; Pebere, N.; Takenouti, H.; Srhiri, A.; Mankowski, G. Quantitative characterization of protective films grown on copper in the presence of different triazole derivative inhibitors. Electrochim. Acta 2002, 47, 4339-4346. [CrossRef]

14. Lewis, G. The corrosion inhibition of copper by benzimidazole. Corros. Sci. 1982, 22, 579-584. [CrossRef]

15. Kuznetsov, Y.I.; Thomas, J.G.N.; Mercer, A.D. Organic Inhibitors of Corrosion of Metals; Springer Science \& Business Media: New York, NY, USA, 1996; ISBN 978-1-4899-1958-8. [CrossRef]

16. Zhang, D.Q.; Gao, L.X.; Zhou, G.D. Synergistic effect of 2-mercapto benzimidazole and KI on copper corrosion inhibition in aerated sulfuric acid solution. J. Appl. Electrochem. 2003, 33, 361-366. [CrossRef]

17. Zhang, D.Q.; Gao, L.X.; Zhou, G.D. Inhibition of copper corrosion in aerated hydrochloric acid solution by heterocyclic compounds containing a mercapto group. Corros. Sci. 2004, 46, 3031-3040. [CrossRef] 
18. Zhang, D.Q.; Gao, L.X.; Zhou, G.D. Inhibition of copper corrosion by bis-(1-benzotriazolymethylene)-(2, 5-thiadiazoly)-disulfide in chloride media. Appl. Surf. Sci. 2004, 225, 287-293. [CrossRef]

19. Antonijevic, M.M.; Petrovic, M.B. Copper Corrosion Inhibitors. A review. Int. J. Electrochem. Sci. 2008, 3, $1-28$.

20. Blajiev, O.; Hubin, A. Inhibition of copper corrosion in chloride solutions by amino-mercapto-thiadiazole and methyl-mercapto-thiadiazole: An impedance spectroscopy and a quantum chemical investigation. Electrochim. Acta 2004, 49, 2761-2770. [CrossRef]

21. Issa, I.M.; Issa, R.M.; Temerk, Y.M.; Ghoneim, M.M. Die Reaktionen der Benzoyl- und Salicoylhydrazone des Vanillins, Furfurols und Zimtaldehyds mit zweiwertigen Ionen der Übergangsmetalle. Monatsh. Chem. 1973, 104, 963-972. [CrossRef]

22. Issa, R.M.; Temerk, Y.M.; Mahmoud, M.R.; Khattab, M.A. Die Chelate von Co (II), Ni (II), Cu (II), Zn (II) und Cd (II) mit Malonsäurehydrazid und dessen Arylidenderivaten. Monatsh. Chem. 1976, 107, 485-493. [CrossRef]

23. Tan, Y.S.; Srinivasan, M.P.; Pehkonen, S.O.; Chooi, S.Y. Effects of ring substituents on the protective properties of self-assembled benzenethiols on copper. Corros. Sci. 2006, 48, 840-862. [CrossRef]

24. Singh, M.M.; Rastogi, R.B.; Upadhyay, B.N.; Yadav, M. Thiosemicarbazide, phenyl isothiocyanate and their condensation product as corrosion inhibitors of copper in aqueous chloride solutions. Mater. Chem. Phys. 2003, 80, 283-293. [CrossRef]

25. El-Maksoud, S.A.A. Some phthalazin derivatives as non toxic corrosion inhibitors for copper in sulphuric acid. Electrochim. Acta 2004, 49, 4205-4212. [CrossRef]

26. Kuznetsov, Y.I.; Agafonkina, M.O.; Shikhaliev, H.S.; Andreeva, N.P.; Potapov, A.Y. Adsorption and passivation of copper by triazoles in neutral aqueous solution. Int. J. Corros. Scale Inhib. 2014, 3, 137-148. [CrossRef]

27. Sasse, K.; Niedrig, H. Kohlensäure-Derivate von 3-Alkylthio-5-amino-und 3-Alkylsulfonyl-5-amino-1,2,4-triazolen. Angew. Chem. 1981, 93, 835-836. [CrossRef]

28. Mansfeld, F. Tafel slopes and corrosion rates obtained in the pre-Tafel region of polarisation curves. Corros. Sci. 2005, 47, 3178-3186. [CrossRef]

29. Shih, H.; Mansfeld, F. Software for quantitative analysis of polarisation curves. Comput. Model. Corros. ASTM Int. 1992, 174-183. [CrossRef]

30. Frisch, M.J.; Trucks, G.W.; Schlegel, H.B.; Scuseria, G.E.; Robb, M.A.; Cheeseman, J.R.; Scalmani, G.; Barone, V.; Petersson, G.A.; Nakatsuji, H.; et al. Gaussian 16, Revision B.01; Gaussian, Inc.: Wallingford, CT, USA, 2016.

31. Parr, R.G.; Pearson, R.G. Absolute hardness: Companion parameter to absolute electronegativity. J. Am. Chem. Soc. 1983, 105, 7512-7516. [CrossRef]

32. Chirkunov, A.A.; Kuznetsov, Y.I.; Shikhaliev, K.S.; Agafonkina, M.O.; Andreeva, N.P.; Kazansky, L.P.; Potapov, A.Y. Adsorption of 5-alkyl-3-amino-1, 2, 4-triazoles from aqueous solutions and protection of copper from atmospheric corrosion. Corros. Sci. 2018, 144, 230-236. [CrossRef]

33. Kuznetsov, Y.I.; Andreeva, N.P. The designing of nanometer-sized passive films at metal surfaces using organic inhibitors. Russ. J. Electrochem. 2012, 48, 442-449. [CrossRef]

34. Chira, A.; Bucur, B.; Radu, G.L. Electrodeposited Organic Layers Formed from Aryl Diazonium Salts for Inhibition of Copper Corrosion. Materials 2017, 10, 235. [CrossRef] [PubMed]

(C) 2019 by the authors. Licensee MDPI, Basel, Switzerland. This article is an open access article distributed under the terms and conditions of the Creative Commons Attribution (CC BY) license (http://creativecommons.org/licenses/by/4.0/). 